\title{
Navigating discourses in place in the world of Webkinz
}

\author{
Karen E. Wohlwend \\ Sarah Vander Zanden \\ Nicholas E. Husbye \\ Candace R. Kuby \\ Indiana University, USA
}

\begin{abstract}
Manuscript accepted for publication
In the Journal of Early Childhood Literacy, 11(2)
\end{abstract}

Special Issue on Geosemiotics, June 2011 


\begin{abstract}
Geosemiotics (Scollon and Scollon, 2003) frames this analysis of play, multimodal collaboration, and peer mediation as players navigate barriers to online connectivity in a children's social network and gaming site. A geosemiotic perspective enables examination of children's web play as discourses in place: fluidly converging and diverging interactions among four factors: 1) social actors, 2) interaction order, 3) visual semiotics, and 4) place semiotics. The video data are excerpted from an ethnographic study of a computer club for primary school-aged children in an after-school program serving working and middle class families in a US Midwest university community. Discourses of schooling in the computer room and Webkinz complicated children's goal of coordinated game play and mutual participation in online games. Barriers to online connection produced ruptures that foregrounded childrens' collaborative management of time and space. This foregrounding makes typically backgrounded practices, modes, and discourses visible and available for deconstruction and critique.
\end{abstract}

\title{
Keywords
}

Discourses in place, virtual worlds, online play, peer mediation, nexus analysis, multimodal analysis 


\section{Introduction}

In this article, we examine online activity in Webkinz (Ganz), a toy-based social networking and gaming website to understand how young children's navigation of avatars within a virtual world engages two key aspects of participatory culture: collaboration and online connectivity, with varying degrees of success. We look at the ways children mediate space-time in their attempts to connect in an online 'club,' a place that blurs distinctions between digital communities and hereand-now friendships, between animated screen characters and inanimate stuffed toys, between schoolwork and after-school play, and between the discourses that circulate in classrooms and gamer communities. What barriers do children encounter as they navigate the interconnected embodied spaces in an afterschool computer club and virtual spaces in Webkinz? What 'discourses in place' (Scollon and Scollon, 2003) are animated as children travel in and out of screen environments while trying to play together as onscreen avatars in these web/toy hybrids?

\section{Web/toy hybrids and young children}

Webkinz is a closed social network with safeguards that require users to register and log-in, designed to protect children but also to restrict access to consumers who have purchased a Webkinz toy. Each toy comes with a secret code that activates the registration process and serves as a key to unlock the Webkinz virtual world. Members play in this online community through animated avatars that match the purchased stuffed animals, producing hybrids that represent children and their toy pets. Once online, children can play games, buy food, clothing, or furniture, furnish their avatars' bedrooms, or communicate with other players through simplified chat and email functions. Like Web 2.0 adult social networks, Webkinz members can also send gifts to each other (as in Facebook), or arrange to meet a friend's avatar in a specified location (as in Second Life) in order to play games together in the Webkinz clubhouse or their avatars' 
rooms. Unlike adult social networks, the content of 'Kinzchat' messages is limited to predetermined partial sentences that children can combine to create statements and questions. In this article, we suggest that despite these limitations when children play Webkinz in the same space such as an after-school club, they can work around website restrictions to connect with other players through online avatars as children sit side-by-side in front of computer monitors.

We know relatively little about young children's online play, in comparison with the digital practices of older children, adolescents, and adults. Numerous studies show that many pre-teens and adolescents access social media and easily engage spatialized literacies (Leander and Sheehy, 2004), that blur boundaries across time and space in complex digital networks and interactive environments (Leander and McKim, 2003). Far less attention has focused on how young children play and represent selves in online social networks, despite burgeoning web/toy hybrids such as Webkinz.

Social networks for children are immensely popular, particularly toy-based game sites such as Webkinz. Such sites operate according to a Web 2.0 discourse that 'values and promotes three interlocking functions or practices: participation, collaboration, and distribution' (Knobel and Wilbur, 2009: 21) as users meet, chat, play games, and share information.

Children's online virtual worlds — simulated environments in which users inhabit and interact with each other via digital representations of themselves called avatars — have become immensely popular....Most surprising, Hitwise's June 2007 ranking of virtual worlds revealed that youth-focused sites (webkinz.com, clubpenguin.com, stardoll.com, habbo.com) held four of the top five spots, rating higher than popular, adult-oriented equivalents, Second Life and World of Warcraft 3....The overwhelming commercial 
success of such Web destinations has encouraged others to jump in, resulting in the emergence of an entirely new category — web/toy hybrids (Shuler, 2007).

Marsh (2010) examined children's social networking and online play in virtual worlds, suggesting the need for research that examines the identity work in the complicated mesh of play, children's desires, consumer practices, and corporate agendas. Burke and Rowsell (2009) focused specifically on digital practices in Webkinz, using an adapted literacy framework to chart complex practices in young child's readings of screen designs and discursive structures. These studies suggest the need for in-depth ethnographic studies that examine how children use web/toy hybrids to enact digital identities, collaborate in virtual play, and navigate complex spaces in social networking sites.

\section{Researching web play as discourses in place}

In this article, we extend the emerging research on web/toy hybrids to understand how young children actually participate in online social networks. Specifically, we use a geosemiotic (Scollon and Scollon, 2003) framework to follow children's attempts to collaborate and navigate screens, web/toys, and space-time. This geosemiotic perspective enables examination of children's web play as discourses in place: fluidly converging and diverging interactions among four factors: 1) social actors, 2) interaction order, 3) visual semiotics, and 4) place semiotics. Frustrations and disruptions caused by discourses in place are apparent in the following excerpt of Webkinz play in an afterschool program for young children.

'Do you see me? You don't even see me?' Julie reaches over to point out her brown horse avatar that has just materialized in one of the chairs in the virtual bowling alley on Carter's computer screen. Julie and Carter regularly sit at adjacent computers during 
Webkinz Club, a weekly activity that takes place in the crowded computer room of an after-school program. Just outside the door, more 5-to 8-year-olds queue up as they wait for free computers, producing a steady stream of players in and out of the computer lab. When club members enter the computer room, they pick up their favorite Webkkinz, perch the stuffed toys near monitors, and quickly log in to begin playing games on the Webkinz website. A loudspeaker contributes to the general noise level in the room, intermittently booming an adult voice that directs individual children to 'come to the front desk, your ride is here.'

Carter, a relative newcomer to Webkinz, and Julie, a more experienced player, are trying to coordinate on-screen actions so that their avatars can play an on-screen bowling game together in the same virtual bowling alley. When Julie locates and enters the Clubhouse bowling alley, Carter helps her maneuver her avatar to the lane where his avatar is standing. The children believe that because their avatars are standing side by side and near the same lane, they will be able to play a two-player game of bowling together. However, when they click to start the game, they are shocked to find they each have a new unknown opponent: Carter's onscreen opponent is a cow avatar instead of Julie's horse. They try again, this time synchronizing the timing of their clicks, '1-2-3, press!' Next, a tiger appears in the opponent's box on Carter's screen. They try again, '1-2-3, press!' but this time a pig appears. Seven-year-old Julie punctuates each failed attempt with 'Aw come on!'finally throwing up her arms in frustration. But after the third attempt, they give up and proceed to bowl separate games, 'Oh well.' 
As these social actors, two seven-year-old children, coordinated the images and animation on a computer screen, they drew upon their shared histories of embodied practices, or habitus (Bourdieu, 1977), that made up the routine ways of talking, playing, and turn-taking in the computer room space. These practices involve physical actions with here-and-now objects (e.g., moving a computer mouse, pressing keys on a keyboard) that mediate, or meaningfully alter (Vygotsky, 1934/1978; Wertsch, 1991) the activity in a virtual environment (e.g., make an avatar move across a screen). Mediated actions are made meaningful when they are categorized as social practices (e.g., chatting, clicking a link, scrolling, browsing) within the local network of commonplace practices in the Webkinz community or an afterschool computer room (Scollon, 2001). These actions can be uncovered and examined through a process that Scollon and Scollon (2004) have called nexus analysis. Nexus analysis uses an action-oriented lens to look at the mergers of bodies, social groupings, and materials meanings within discourses in place, looking among nexus of typical practices to locate transformative moments (where things change to further participants' interests).

Interaction order describes how practices fit into patterns of relationships among social actors, such as 'singles', 'queues', or 'withs' (Goffman, 1971). For example, singles describe children playing alone at a computer while queues describe children who organized themselves into a sequence while waiting for a turn in the computer room. Withs describe relationships where 'two or more who are perceived as being together with each other as the main focus of their mutual attention' (Scollon and Scollon, 2003: 61). Julie and Carter's shared activity forms a with in the computer room that extends into the virtual bowling alley as they work diligently to maintain their virtual connection. In the initial pass through video data, we identified withs (i.e., events where two or more children worked together on shared goals across computers). We 
found that maintaining these withs often involved 1) peer mediation (e.g., one child taught another child how to access a game or complete a Webkinz task) and/or 2) online connection (e.g., two or more children accessed the same screen together on two or more computers).

Further, peer mediation and online connection formed an important intersection or nexus of practice (Scollon, 2001) as children taught each other to navigate to the same screen. Nexus are dense knots of actions that served as tacit markers of membership and expertise in the computer room peer culture. The nexus of peer mediation and online connection frequently occurred together in ways that furthered children's shared goals and demonstrated value among club members: members would leave their own computers and walk across the room to help peers, or seek help from peers, in order to access the same screen or add each other to their lists of friends. Such synergies in nexus produce transformation: for example, we expected peer mediation and working across connected screens would result in identity work around the transformation from the player with to an avatar with. However, we found that children could not transform their here-and-now withs into on-screen withs (e.g., to play a multiplayer game together). To understand why, we used additional geosemiotic lenses to look closely at computer screens and environmental contexts to identify possible barriers: visual semiotics and place semiotics.

Visual semiotics enables reading of computer screens in ways that reveal the social effects of print or image in Webkinz animation. Mode-oriented lenses enabled by geosemiotic analysis allowed us to look again at the same mergers (bodies, social orders, materials, discourses in place) to see how children made sense and made use of the print, image and other modes on-screen and in the surrounding environment. Norris ${ }^{1}$ (2004) interactional approach to

\footnotetext{
${ }^{1}$ Scollon and Scollon (2003) draw upon Kress' social semiotic theory to conceptualize visual and place semiotics. Consistent with Scollon's action-oriented focus (2001), Sigrid Norris, looks at modes from a sociolinguistic and
} 
multimodal analysis looks at how meanings are shaped as our attention shifts among modes, the intertwining aspects of lived interaction among actors, materials, and environments. This contrasts with Kress' (2009) social semiotic definition of modes as culturally-shaped resources for representation with particular affordances for actors' intended designs. Visual semiotics explains how varying attention to modes (e.g., print, image, or gaze) in screen layout and design elements influence meanings and user identities. For example, Webkinz help menu screen designs rely extensively on verbal information: blocks of text for player to scroll through and read, embedded pop-up screens and help menus organized as books, and on large cartoon characters who speak to introduce new activities on opening screens. These features anticipate that players will be able to read or seek the help of readers when they get stuck in the game. Place semiotics widens the focus to include auditory, action, and environmental modes and looks closely to see how the children's manipulation of multiple modes worked around barriers in the computer room and in the Webkinz virtual world as they maneuvered their pets/avatars moves and pretended to play together online. Norris' identifies a range of modes beyond visual, including:

- auditory (e.g., speech, music, and sound-effect)

- action (e.g., gesture, posture, movement, facial expression, touch, and manipulation of objects including mediated actions with books, writing tools, or art materials) environmental (e.g., built environment, proximity [near/far relationships])

To identify multimodal relationships, video data from two cameras in the computer room were simultaneously analyzed so that closeup shots of screen images on children's individual 
computers were synchronized with mid-range shots of pairs of children seated at computers. These short sequences were analyzed to locate overlapping modes (e.g., space-time, speech, gaze, mediated action). Images and activity across multiple screen shots were analyzed to see how relationships among auditory, visual, action, and environmental modes reflected dominant discourses and shaped connections among children as they played Webkinz. Place semiotics allowed us to examine how children read the 'in place' meanings of screen content as they worked together to manipulate space-time as they tried to achieve an online connection. We take an expanded view of the mode of proximity (Norris, 2004) to consider the broader notion of space-time. Thinking of space-time as a mode allows us to consider more than static placement in a fixed physical distance but also to see the children's navigation of animation as moves among many interacting modes on screens and in the computer room.

Interaction among clustered modes produces semiotic and social effects by foregrounding some modes and backgrounding others. Each mode has expected uses (or non-uses) legitimated by one or more discourses. The ways in which some modes are restricted and other modes are enhanced reveals discourses at work in a place. A place, whether a virtual pet world or an afterschool computer club, is a 'semiotic aggregate' made up of multiple discourses in place. Discourses legitimate ways of doing things in Webkinz, whether bowling with an avatar or playing digital games with a friend, across lived/virtual spaces where social actors, interaction orders, visual and place semiotics come together.

\section{Navigating the world of Webkinz Research context} The featured vignette is excerpted from a one-year study of children's online play with web/toy social networking sites. The research took place in the computer lab of a not-for-profit after- 
school program for elementary school-aged children; the program served primarily working and middle class families in a US Midwest university community. Thirty-five children (5- to 8-year olds) were enrolled in the Webkinz Club that met weekly for one hour sessions during one semester. During Webkinz club sessions, we distributed Webkinz toys, assisted children in logging on, and videotaped as children played with web/toys on the Webkinz website in the computer lab. Each child chose a Webkinz toy and entered its user name and password in a shared account (i.e., all toys and web accounts were shared among the children and the stuffed animals were distributed each week to the first child who asked for a particular toy.) Children independently logged in and selected from a range of available activities that included: earning Kinzcash by playing arcade games or performing jobs such as making hamburgers, meeting other players at the Kinz Clubhouse to chat or play games such as checkers or bowling, buying furniture to decorate the pet's room, taking the pet to the clinic, and buying clothing or food for the pet. (Children were also able to access the Webkinz accounts at other times and play on their own during the rest of the week in the computer room or at home).

\section{Social actors and Webkinz Club practices}

The Webkinz Club operated as a community of practice (Lave and Wenger, 1991) in which children learned to navigate websites and maneuver avatars through mediated encounters with technology, coached by other club members. Children learned ways of handling the computer mouse as they moved a cursor across the screen, animated an avatar, or produced virtual goods. Children heavily engaged in playing-accruing-buying sequences, that is, selecting and playing an arcade game in order to earn lots of Kinzcash (e.g., spinning the Wheel of WOW), and then redeeming Kinzcash at the Webkinz shopping outlet in order to purchase items for avatars (e.g., buying a new chair for a pet's room). 
When children watched adjacent screens and followed their neighbors to explore new games, they engaged in parallel play on matching screens. Additionally, children often checked neighbors' screens and offered unsolicited advice on playing a game 'I can get past that' or recommended a site, 'You should go here.' This in turn prompted the other player to ask for help. Direct requests for peer assistance most often arose from procedural questions 'How do I do that?' as children went about learning a new sequence and navigating to an unfamiliar place: Lamont, sitting next to Hannah, notices that she has a phone at the bottom of her screen and asks, 'How do I do that?' Hannah leaves her computer, walks over, and peers into Lamont's screen. Taking his mouse, she navigates to My Room, opens the phone, and adds her user name before handing the mouse back to him. She watches him for a moment and returns to her own computer. As soon as she sits down, Lamont asks Hannah, 'Can I call you?' Hannah leans across and works with Lamont to set up a friend link on his phone. He tries to call, unsuccessfully. She asks Lamont, 'What's your user name?' and types it into the phone on her own screen, a necessary step to receive his calls. However, Lamont has moved on to a new game and does not call again.

The desire to navigate to the same screen prompted peer mediation as did attempts to add friends or set up phones for chatting when children needed to share information such as user names or give explanations or demonstrations of the necessary steps. Further as Hannah's case demonstrates, peer mediation depended upon a willingness to stop playing and leave one's own computer to mentor a friend. In this typical instance, the children did not establish an online with (e.g., phone call, chat, multiplayer game). In the following section, we take a close look at one instance of peer mediation and online connectivity to understand how discourses of gaming and schooling came together across places to produce complexity and barriers to virtual withs. 


\section{Interaction order and attempts to play together in an online with}

'Do you see me? You don't even see me?' In the moment transcribed in Tables 1 and 2, Julie and Carter were trying to coordinate screens so that they could play a game of bowling in the Clubhouse. Their shared desire to play together onscreen demonstrates their status as a with. They knew from previous attempts with other games that just standing in the same computer room would not ensure that they could begin a new bowling game together. So after Carter helped Julie locate and enter the bowling alley, they coordinated their timing to simultaneously begin a bowling game. Carter helped her to move her horse avatar around to the lane where his leopard avatar was standing (Table 1, Line 4), coordinating space-time to achieve virtual proximity on their screens. This allowed them to project their here-and-now with in the computer room to an online within the Webkinz bowling alley. They also believed that because their avatars were standing side by side and near the same lane on screen, they would be able to play a two-player game together. However, when they clicked to start the game, each child had a new opponent representing a computer-generated player (Table 2, Line 6). Carter was playing a cow avatar instead of Julie's brown horse. They tried again and this time developed a strategy to synchronize their timing, '1-2-3, press!' however a tiger appeared as Carter's opponent (Table 2, Line 8). They tried a third time, '1-2-3, press!' and this time, a pig appeared in the opponent's box (Table 2, Line 9). The children finally give up and continue bowling in separate games. 
Table 1. 'Do you see me?' Locating and maneuvering avatars in bowling alley room

\begin{tabular}{|c|c|c|c|c|c|}
\hline & C's Screen Image & Mediated Action & $\begin{array}{l}\text { Game Meanings } \\
\text { and Screen } \\
\text { Strategies } \\
\end{array}$ & Talk & $\begin{array}{l}\text { Player Identities } \\
\text { and Participation } \\
\text { Goals } \\
\end{array}$ \\
\hline 1 & $\begin{array}{l}\text { Bowling Alley } \\
\text { Room: }\end{array}$ & $\begin{array}{l}\text { C clicks on a floor } \\
\text { tile to move his } \\
\text { leopard avatar to the } \\
\text { green chairs on the } \\
\text { bottom right. J's } \\
\text { brown horse has just } \\
\text { materialized on C's } \\
\text { screen sitting on } \\
\text { center green chair }\end{array}$ & $\begin{array}{l}\text { J's horse avatar } \\
\text { enters bowling alley } \\
\text { game room and } \\
\text { begins a game of } \\
\text { checkers } \\
\text { C's leopard walks } \\
\text { over to green chair, } \\
\text { past other avatars and } \\
\text { stops next to J's } \\
\text { horse }\end{array}$ & $\begin{array}{l}\text { J: Do you see me? } \\
\text { You don't even see } \\
\text { me? } \\
\text { C: You're playing. }\end{array}$ & $\begin{array}{l}\mathrm{J} \text { and C: Co-players } \\
\text { Joining friend in } \\
\text { same room }\end{array}$ \\
\hline 2 & $\begin{array}{l}\text { Bowling Alley } \\
\text { Room: }\end{array}$ & $\begin{array}{l}\text { C clicks on/floor tile } \\
\text { [moves leopard to } \\
\text { middle lane; } \\
\text { circles cursor close to } \\
\text { green chairs; } \\
\text { clicks on/floor tile } \\
\text { [moves leopard to } \\
\text { left lane lane]; circles } \\
\text { cursor; } \\
\text { clicks on/floor tile } \\
\text { [moves leopard to } \\
\text { center lane] }\end{array}$ & $\begin{array}{l}\text { C's leopard walks } \\
\text { around bowling alley } \\
\text { past other avatars } \\
\text { Intuitive game } \\
\text { strategies: } \\
\text { Moving close to } \\
\text { likely portals to } \\
\text { trigger game } \\
\text { Rolling over items on } \\
\text { screen for potential } \\
\text { pop-ups } \\
\text { Searching for live } \\
\text { links }\end{array}$ & $\begin{array}{l}\text { J: Now, I see you. } \\
\text { Carter. Wait! Carter, } \\
\text { hold on! Get out, get } \\
\text { out! Hold on. Carter, } \\
\text { see me? I'm right } \\
\text { there! }\end{array}$ & $\begin{array}{l}\text { J: Co: player } \\
\text { C: Independent } \\
\text { Explorer } \\
\text { Coordinate shared } \\
\text { gaze } \\
\text { Virtual proximity: } \\
\text { maneuvering to same } \\
\text { spot in the same } \\
\text { room }\end{array}$ \\
\hline
\end{tabular}


Table 1. 'Do you see me?' Locating and maneuvering avatars in bowling alley room

\begin{tabular}{|c|c|c|c|c|c|}
\hline 3 & $\begin{array}{l}\text { Bowling Alley } \\
\text { Room: }\end{array}$ & & $\begin{array}{l}\text { J's horse avatar } \\
\text { sitting on green chair } \\
\text { playing board games; } \\
\text { C's leopard stands } \\
\text { next to far right lane }\end{array}$ & $\begin{array}{l}\text { J: See me? I don't } \\
\text { know how to get him } \\
\text { off! How do I get } \\
\text { him out? F---ing, } \\
\text { how do I get him } \\
\text { out? }\end{array}$ & $\begin{array}{l}\text { J: Bowling Novice } \\
\text { Appeal for help with } \\
\text { stuck place }\end{array}$ \\
\hline 4 & $\begin{array}{l}\text { Bowling Alley } \\
\text { Room: }\end{array}$ & $\begin{array}{l}\text { C reaches for J's } \\
\text { mouse and takes it } \\
\text { from her, } \\
\text { simultaneously using } \\
\text { left hand to push J's } \\
\text { hand away and right } \\
\text { hand in position to } \\
\text { click mouse. C } \\
\text { circles cursor around } \\
\text { floor tile. J reaches } \\
\text { for her own mouse, } \\
\text { covering C's hand } \\
\text { with hers. J removes } \\
\text { her hand. }\end{array}$ & $\begin{array}{l}\text { J's horse avatar } \\
\text { moves off green } \\
\text { game chair and } \\
\text { moves across room } \\
\text { to C's leopard avatar }\end{array}$ & $\begin{array}{l}\text { J: I don't know how } \\
\text { to get him off. I'm } \\
\text { sitting- } \\
\text { J: Watch! Switch } \\
\text { rooms, I'll go back. } \\
\text { C: No! I got it. }\end{array}$ & $\begin{array}{l}\text { J: Bowling Novice } \\
\text { C: Mentor } \\
\text { Here-and-Now } \\
\text { Mediation: Taking } \\
\text { over J's mouse in } \\
\text { response to her } \\
\text { frustration. } \\
\text { Virtual proximity: } \\
\text { maneuvering avatars } \\
\text { to same spot in the } \\
\text { same room }\end{array}$ \\
\hline
\end{tabular}


Close analysis of Julie and Carter's interaction shows that maintaining this 'double with' involved intense coordination of relationships between their avatars, computers, and each other. Their conversation is filled with directives that fluidly shifted between directing each other as coplayers 'Wait! Carter, hold on!' (Table 1, Line 2) and speaking directly to their avatars 'Get out [of the chair], get out!' (Table 1, Line 2 continued). Identities flowed through these shifts, evident in pronouns: they referred to their own avatars in first person, 'Do you [Carter as player] see me [Julie as avatar]?' (Table 1, Line 2) and their friend's avatar in second person. 'Now I [Julie as player] see you [Carter as avatar]' (Table 1, Line 3). As Julie's frustration grew, the player/avatar connection and play frame (Goffman, 1971) broke down and her 'uncooperative' avatar became an object to be maneuvered in the game: 'See me [Julie as avatar]? I don't know how to get him [avatar as object/pet] off! How do I get him out?' (Table 1, Line 3). Breaks in frame happen in collaborative play when shared meaning breaks down and children stop pretending to step outside the play frame and renegotiate whose character can do what. Carter responds to Julie's explicit plea, 'How do I get him out?' by taking over her mouse and maneuvering her avatar next to his own. Although they were able to navigate to the same bowling alley and stand next to each other's avatars, there was no assurance that achieving onscreen proximity would allow them to maintain an online with and synchronize bowling in virtual space.

\section{Reading screens for visual semiotics}

Interestingly, there is a way in which players can arrange to play a game together online: by coordinating their friend zone colors on their chat phones, selecting the same game room at the Clubhouse, typing in the same room number, and finally choosing multiplayer network option. 
Disruptions were produced in part by a reliance on print in individual screens and in the navigation system that sets up pre-determined pathways. The Webkinz Clubhouse uses a printcentric navigation path that does not enable easy connectivity for novice players. In order to successfully play each other in a virtual bowling game, children must first enter the 'Clubhouse: Kinzchat Room' and locate a small button 'Find My Friends' on the bottom of the opening bulletin board that serves as an index page for the game rooms in the Clubhouse. Before clicking this button, the players need to both power up their KinzChat phones and also coordinate their phone color zone (blue, yellow, green or pink) in order to show up as friends on the Find My Friends locator screen, indicated by a green smiley face by each player's user name. (This step must be repeated often as phones automatically change to new zone colors when inactive). Players then select a friend's user name and click the 'Join My Friends' button. Once in the appropriate game room with friends, players need to locate the portal that launches the game: in the bowling alley, players must click somewhere on one of the lanes to launch the KinzPinz title screen (Table 2, Line 5). On the KinzPinz screen, they must then choose the correct button to enable a multiplayer game. The screen provides the following options: ' 1 player game', ' 2 player game', or 'multiplayer network' (Table 2, Line 7). In order for players to play each other in the same game, children must select 'multiplayer network.' However, Julie and Carter, repeatedly selected ' 2 player game', thinking this would allow two players to play one another. When they simultaneously clicked the '2 player game', computer-generated avatars always appeared as their opponents (Table 2, Lines 8, 9). 


\begin{tabular}{|c|c|c|c|c|c|c|}
\hline & $\begin{array}{l}\text { Carter's Screen } \\
\text { Image }^{2}\end{array}$ & $\begin{array}{l}\text { Mediated } \\
\text { Action }\end{array}$ & $\begin{array}{l}\text { Game Meanings } \\
\text { and Strategies }\end{array}$ & Talk & $\begin{array}{l}\text { Player } \\
\text { Identities and } \\
\text { Participation } \\
\text { Goals }\end{array}$ & $\begin{array}{l}\text { Modes/Discourses } \\
\text { (Foregrounded in } \\
\text { Bold) }\end{array}$ \\
\hline 5 & $\begin{array}{l}\text { KinzPinz Title } \\
\text { Screen }\end{array}$ & $\begin{array}{l}\text { J: Raises hands } \\
\text { above head. } \\
\text { C: Monitors } \\
\text { Julie, watches } \\
\text { her screen, } \\
\text { checks his own } \\
\text { screen }\end{array}$ & $\begin{array}{l}\text { J starts two } \\
\text { player game and } \\
\text { waits for C } \\
\text { Using visual } \\
\text { information to } \\
\text { verify location } \\
\text { on } 2 \text { screens }\end{array}$ & $\begin{array}{l}\text { J: C'mon, c'mon! } \\
\text { C: I already did. } \\
\text { J: I can't. }\end{array}$ & $\begin{array}{l}\text { C: Independent } \\
\text { player } \\
\text { J: Co-player } \\
\text { Virtual } \\
\text { proximity: to } \\
\text { select the same } \\
\text { button to play } \\
\text { together in the } \\
\text { same onscreen } \\
\text { game }\end{array}$ & $\begin{array}{l}\text { Gaze/Web 2.0. } \\
\text { Space-Time/ Web } \\
\text { 2.0 } \\
\text { Speech/Web 2.0. } \\
\text { Sound/Adult } \\
\text { Authority } \\
\text { [muted] } \\
\text { Mediated Action: } \\
\text { Web 2.0. } \\
\text { Print/Adult } \\
\text { Authority }\end{array}$ \\
\hline 6 & $\begin{array}{l}\text { KinzPinz Game } \\
1 \text { with cow } \\
\text { opponent screen }\end{array}$ & $\begin{array}{l}\text { C: Clicks on/X } \\
\text { [exit bowling } \\
\text { game } 1 \text { with } \\
\text { cow] }\end{array}$ & $\begin{array}{l}\text { Carter clicks to } \\
\text { start } 2 \text { player } \\
\text { game, sees Julie } \\
\text { is not opponent, } \\
\text { exits game } 1 . \\
\text { Verbally } \\
\text { confirms the } \\
\text { button that J } \\
\text { should press. } \\
\text { Visually } \\
\text { coordinating } \\
\text { virtual location }\end{array}$ & $\begin{array}{l}\text { C: Two player } \\
\text { game. J: Two } \\
\text { player? Plea:::se. } \\
\text { Two Player. }\end{array}$ & $\begin{array}{l}\text { C: Mentor } \\
\text { J: Novice } \\
\text { Virtual } \\
\text { proximity: to } \\
\text { select the same } \\
\text { button to play } \\
\text { together in the } \\
\text { same onscreen } \\
\text { game }\end{array}$ & $\begin{array}{l}\text { Gaze/Web 2.0. } \\
\text { Space-Time/Web } \\
\mathbf{2 . 0} \\
\text { Image/ Web 2.0. } \\
\text { Speech/ Web 2.0. } \\
\text { Sound/Adult } \\
\text { Authority } \\
\text { Mediated Action: } \\
\text { Web 2.0. } \\
\text { Print/Adult } \\
\text { Authority }\end{array}$ \\
\hline 7 & $\begin{array}{l}\text { KinzPinz Screen } \\
\text { with options of }\end{array}$ & $\begin{array}{l}\text { C: Clicks } \\
\text { on/two player }\end{array}$ & $\begin{array}{l}\text { Carter has } \\
\text { clicked and }\end{array}$ & $\begin{array}{l}\text { J: M-I'm not } \\
\text { against you }\end{array}$ & $\begin{array}{l}\text { J: Problem solver } \\
\text { C: Problem }\end{array}$ & $\begin{array}{l}\text { Gaze/Web 2.0. } \\
\text { Space-Time/Web }\end{array}$ \\
\hline
\end{tabular}

\footnotetext{
${ }^{2}$ Visit the Webkinz website (http://www.webkinz.com/SWF/TOUR/siteTour.html) for a guest tour to see examples of screen shots including Kinzchat and gaming options.
} 


\begin{tabular}{|c|c|c|c|c|c|c|}
\hline & $\begin{array}{l}\text { player 1, player } \\
\text { 2, multiplayer } \\
\text { network or } \\
\text { instruction } \\
\text { buttons: }\end{array}$ & $\begin{array}{l}\text { game button } \\
\text { [begin game 2] } \\
\text { J: Looks right } \\
\text { over at C's } \\
\text { KinzPinz screen }\end{array}$ & $\begin{array}{l}\text { started game } 2 \\
\text { before Julie } \\
\text { clicks button } \\
\text { Simultaneous } \\
\text { clicking, } \\
\text { correcting } \\
\text { misalignment: }\end{array}$ & $\begin{array}{l}\text { C: Go back, go } \\
\text { back } \\
\text { J: Hold on, wait } \\
\text { for me... } 123 \text {-- } \\
\text { Carter! }\end{array}$ & $\begin{array}{l}\text { solver } \\
\text { Coordination of } \\
\text { here-and-now } \\
\text { and virtual } \\
\text { space-times to } \\
\text { play game } \\
\text { together }\end{array}$ & $\begin{array}{l}\text { 2.0 } \\
\text { Image/Web 2.0. } \\
\text { Speech/ Web 2.0. } \\
\text { Sound/Adult } \\
\text { Authority } \\
\text { Mediated Action: } \\
\text { Web 2.0. } \\
\text { Print/Adult } \\
\text { Authority }\end{array}$ \\
\hline 8 & $\begin{array}{l}\text { KinzPinz Game } \\
2 \text { with tiger } \\
\text { opponent }\end{array}$ & $\begin{array}{l}\text { C: Click on/X } \\
\text { [exit bowling } \\
\text { game } 2 \text { with } \\
\text { tiger] }\end{array}$ & & $\begin{array}{l}\text { J: I'm gonna } \\
\text { count, Carter. } 12 \\
3 \text {, press! }\end{array}$ & J: Innovator & $\begin{array}{l}\text { Gaze/Web 2.0. } \\
\text { SpaceTime/Web } \\
2.0 . \\
\text { Image/Web 2.0. } \\
\text { Speech/ Web 2.0. } \\
\text { Sound/Adult } \\
\text { authority } \\
\text { Mediated Action: } \\
\text { Web 2.0. } \\
\text { Print/Adult } \\
\text { Authority }\end{array}$ \\
\hline 9 & $\begin{array}{l}\text { KinzPinz Game } \\
3 \text { with pig } \\
\text { opponent }\end{array}$ & $\begin{array}{l}\text { J: Raises hands } \\
\text { above head }\end{array}$ & $\begin{array}{l}\mathrm{J} \text { : Frustration and } \\
\text { resignation } \\
\text { C: Moving on, } \\
\text { Trying other } \\
\text { game on own }\end{array}$ & $\begin{array}{l}\text { J: Aw! Come on! } \\
\text { C: Oh well. Who } \\
\text { cares? }\end{array}$ & $\begin{array}{l}\text { J: Frustrated Co- } \\
\text { player } \\
\text { C: Independent } \\
\text { Player } \\
\text { Moving on to } \\
\text { play } \\
\text { simultaneously } \\
\text { in different } \\
\text { rooms; co- } \\
\text { playing by } \\
\text { watching across } \\
\text { screens. }\end{array}$ & $\begin{array}{l}\text { Gaze/Web 2.0. } \\
\text { Space-Time/Web } \\
2.0 . \\
\text { Image/Web 2.0. } \\
\text { Speech/ Web 2.0. } \\
\text { Sound/Adult } \\
\text { Authority } \\
\text { Gesture/Web 2.0. } \\
\text { Mediated Action: } \\
\text { Web 2.0. } \\
\text { Print/Adult } \\
\text { Authority }\end{array}$ \\
\hline
\end{tabular}


Maneuvering avatars to the same bowling alley and selecting the correct game option is still not enough to allow players to achieve their goal of playing each other. If both players select 'multiplayer network' at the same time, it voids their attempt as each player will appear to be already engaged in a game. Instead one player must select 'multiplayer network' first, open the game, and then select the second player's avatar while that player waits in the game room. Carter and Julie finally gave up and chose to play at online bowling while sitting side-by-side, each playing a computer-generated avatar and commenting on the other's game.

\section{Mapping modes in place semiotics}

When we analyzed modes in the Julie and Carter's KinzPinz play in the context of the computer room, we saw that their interaction across digital and face-to-face spaces foregrounded and integrated multiple modes: space-time, speech, gaze, image, and the mediated action of clicking ${ }^{3}$, that is, coordination of these modes was essential for the children's goal of establishing the virtual with onscreen and maintaining the embodied with in the computer room as the two children worked to sustain an online connection and their offline friendship.

\section{Speech and sound}

Speech was everywhere, not only between the two children but as a constant interruption that ran in the background as the loudspeaker regularly broadcasted announcements that called children to the main desk when their parents arrived to pick them up. The computer room buzzed with the sounds of other children's conversations 'How'd you get that?' as well as the noise of mouse clicking and keyboard tapping. But the computers were muted to prevent sound effects: one of

Due to space considerations, we focus here on two discourses to show how they are associated with print, image, speech, sound, and space-time. In any given instance of lived experience however, multiple discourses and modes overlap and interact in complicated ways. 
the computer room rules prohibited children from enabling sound on their computers. The 'speakers off' rule was mandated with good intentions; the staff assumed that children desired quiet, solitary computing spaces. However, the result was that children faced barriers unanticipated by Webkinz (and other websites). The muting of computers blocked Webkinz designers' intentional provision of sound and speech modes that provided spoken guidance for young players.

\section{Proximity and space-time}

Children managed their proximity onscreen as well as in the computer room. Onscreen proximity of avatars was foregrounded in the children's shared goal of connectivity: to place their Webkinz pets in the same virtual time and space. Close proximity of children in the here-and-now computer room enabled the key practice of mediation through related modes: talking, gesturing to another's screen, and temporarily taking over a peer's mouse. In this event, the mode of spacetime was modally complex — integrating and involved other modes — by enabling the use of gaze, image, and gesture: as children gazed together at screen images, touched and gestured to coordinate the location of their avatars, and synchronized their mouse-clicking actions with speech, '1-2-3-Click!' (Table 2, Line 8).

The Webkinz Club enabled close embodied and virtual proximity that supported social relationships and allowed children to attempt to play together in ways that would not be possible for children either playing at home or playing at isolated computers surrounded by Wizard 101 players. Manuevering their avatars into the same space was of intense interest to Carter and Julie but Carter's avatar also walked by other players' avatars in the virtual bowling alley (Table 1, Lines 1,2). Although the unknown players' avatars were in close proximity to Carter's leopard, this proximity did not matter to Carter. The proximity of anonymous avatars only mattered in the 
sense that he needed to visually check to see if each could be Julie's horse avatar; after that, unknown avatars became obstacles like furniture, something to maneuver around.

\section{Discourses in place}

\section{Discourse of adult authority}

A discourse of adult authority, embodied in adult staff members who monitored the computer room, circulated an expectation that children should obey adults quickly without question. In the computer room, the modes of speech and sound were heavily controlled by adults through the discourse of adult authority: adults could speak loudly across the room while children were expected to speak quietly to nearby players and to play quietly with no sounds from their computers so that the computer room noise level would allow children to hear their names when adults spoke over the loudspeaker. To ensure this, all computers were muted; adults monitored and only occasionally needed to remind children to turn off the sound. Although these largely unspoken expectations for quiet children and silent computers were backgrounded, they were engrained. Even when we encouraged the children to turn on the sound in order to navigate Webkinz ${ }^{4}$, children hesitated or adjusted the volume so it was barely audible.

A mode is highly foregrounded when it draws actors' attention away from other modes in an event (e.g, the mode of speech as an adult makes announcements over a loudspeaker) or when it is highly interconnected and integrated with other modes (e.g., the mode of speech when accompanied by multiple action and visual modes as children simultaneously work to establish an online connection at adjacent computers). The muting of computers removed key modes such as character speech, sound-effects, and music that the Webkinz site provided to guide children's meaning-making and screen navigation. The silencing of Webkinz characters required children

\footnotetext{
${ }^{4}$ Karen talked with after-school program administrators to get an exception to the muting rule and to develop alternatives to the loudspeaker dismissal system.
} 
to rely on other modes and intensified the modes of gaze, print, and image. Without spoken directions from onscreen characters, children needed to focus on the print and icons in order to make sense of the animation and to navigate the screens.

\section{Web 2.0 discourse}

The children's manipulation of space-time and their desire to play together meshed with values of connectivity and collaborative meaning production, circulated in a new ethos associated with Web 2.0 (Lankshear and Knobel, 2007). In this discourse, print-centric and individuated ways of reading and writing give way to playing and designing in mediated collaborations within online communities. A Web 2.0 (Knobel and Wilbur, 2009) discourse shifts our attention from individual interaction with texts and digital technologies to collaborative connections across networks. Participation is the hallmark of Web 2.0 communities and it takes various forms: forming affiliations through virtual worlds (e.g., Webkinz or Second Life) and social networks (e.g., Facebook or nings), sharing creative expressions (e.g., zines or mashups), collaborative problem-solving (e.g., wikis), and circulations (e.g., podcasts, blogs, tweets) (Jenkins et al., 2006). To participate in a social network is to cooperate with others to collectively-maintain interaction that is 'wired, extroverted and ... augmented by a dense set of technologies, signifiers, and systems of exchange' (Ito, 2007: 42). For Julie and Carter, attempting connectivity in Webkinz required intense concentration on the mode of space-time to synchronize their movements (1-2-3, press!) with computer animation across embodied and virtual spaces. 


\section{Playing around barriers in virtual worlds \\ Barriers to establishing an online with}

Each social actor brings her or his embodied histories or habitus (Bordieu, 1977) into a place. In

this case, Carter and Julie brought prior experiences with computers, arcade games, and Webkinz toys as well as shared histories in the after-school program, including embodied ways of enacting friendships, peer coaching, computer room rules and procedures, and gaming strategies.

These familiar practices shaped the goals of Julie and Carter's activity. 'In a game, the primary social interactions of the participants in a game are focused on the unfolding of their actions in relationship to each other...' (Goffman, 1971: 62). However, important to the study of discourses in place, the ways that people in a with coordinate their activities is backgrounded while the goals of their shared activity is foregrounded and occupies their mutual attention. We can imagine a game of bowling in a brick and mortar bowling alley. Opponents in a game would need to manage space and time to take turns rolling two bowling balls down the same lane. But space-time management through turn-taking is not the focus of their activity; rather their shared goal of competitive game play foregrounds ongoing comparison of scores to see who is winning. We suggest that, for Julie and Carter, play in virtual environments within massive social networks complicated their goal of coordinated game play and mutual participation. The barriers to collaboration produced ruptures that foregrounded proximity by intensifying the need to maintain connections across time and space. This foregrounding makes typically backgrounded practices, modes, and discourses visible and available for deconstruction and critique.

Examination of modal interactions can reveal power relations by indicating the modes and associated discourses that naturalize the typical ways of doing things in a particular place. We argue that the foregrounding and backgrounding of modes reveal power relations among practices, modes, and discourses. Modes realize a child's social interest when certain ways of 
combining modes (e.g., gazing at a computer screen with muted volume, listening to a blaring loudspeaker) support tacitly-valued practices that might get a child recognized as a good club member: working alone, responding quickly when called to the front desk). In this way, power relations are made visible in the embodied activity situated within a particular place when modal combinations for expected practices realize the dominant discourses that legitimate the practices that 'count' in that place. For example, a teacher's insistence on silence and close monitoring of children's speech and sound in classrooms indexes literacy discourses that legitimate scrupulous control of children's bodies in school (Boldt, 2001; Luke, 1992).

\section{Navigating discourses in place}

As children played on the Webkinz site, their moves created trails of game decisions and strategies that involved various levels of mediation: handling a computer mouse, shaping avatar paths, scaffolding other players, and making use of available modes in the surrounding physical and virtual environments. In addition to using modes as immediate resources for mediating onscreen play activity, children's play moves were motivated by their social interest (Kress, 1997). Rowsell and Pahl (2007) have argued that social interest is more than an immediate goal such as trying to bowl with a friend; interest is shaped by habitus and taps into a storehouse of histories of embodied practices and dispositions (Bourdieu, 1977). The semiotic practices used to produce paths through the Webkinz site, whether placing an avatar in position in a game or choosing furniture to design a pet's room, sediment into the artifacts they produce. We argue that digital play sediments a player's gaming habitus into the artifacts produced and saved within Webkinz. Each player's arcade game scores, phone lists of friends, goods purchased from the Webkinz stores, and room layouts stored in the website's databases represent layers of previous play experiences and practices: gaming strategies and discourses, player identities and 
dispositions, and patterns of mouse-handling and familiar paths that navigate avatars around screens.

Although Julie and Carter tried multiple times and ways to coordinate their playing, they could not read the discourses in place to recognize the differences between a two player game and a multiplayer game. Printed directions partially explain this; the reliance on printed text in the directions that appear on several screens in the Webkinz guide reinscribes an adult authority discourse that assumes children will consult a manual rather than trust their own intuitive screen readings. The discourses in place on Webkinz privilege print literacy over other forms of communication but this was further compounded by the discourses in place in the computer room that mandated silent computers.

However, consistent with the collaborative problem-solving envisioned in Web 2.0 discourse, the children ignored onscreen print directions and relied instead upon intuitive interpretations of the placement and proximity of screen elements. They read the layout of the screen and coordinated their gaze, mouse clicks, and avatar movements to navigate the room using their knowledge of video game conventions. The players acted upon embodied habits that taught them to click on objects to locate portals or maneuver avatars by clicking tiles on a floor grid, a gamer's 'intuition' that reflected their Web 2.0 habitus and read screen animation as a discourse in place.

Things mean, in part, 'because of where and how they are placed in the material world' (Scollon and Scollon, 2003). Geosemiotics attends to the ways meanings constitute and are constituted by place, that is, how a place brings together and indexes particular meanings through aspects of the built environment as well as expected interaction orders, available modal resources, and discourses and sedimented practices in materials. The virtual and face-to-face 
environments in this article circulated different discourses in places with different but overlapping meanings and aims: the afterschool computer club is situated in a not-for-profit community service organization that aims to provide free and safe childcare; the World of Webkinz is situated in a toy franchise that aims to entice young consumers to buy and collect its stuffed toys. Both places shared a concern for internet safety; however, Webkinz gatekeeping measures also feed demand for its products by ensuring that players must be purchasers. Safety structures within the game, such as preset dialogue segments in the chat room, restrict freedom for the children but also add a buying incentive for parents concerned about safety precautions. By substituting preset pleasantries for real dialogue or navigation barriers for online decisionmaking, children are protected from external threats. However, children in virtual environments like these are not protected from manufacturers' mass marketing strategies and game structures built upon imperatives to consume.

Clearly, web/toys converge more than toy and avatar or real and virtual environments. Web/toys merge play and discourses with technologies and literacies that coordinate meanings with others across time and space. These converged texts shape children's identities and teach them how to read and respond in particular ways in digital worlds. We need to recognize that web/toys and children's social networking sites teach children important lessons about how to project selves into virtual space as well as how to work together and get things done in Web 2.0 worlds. The recognition that the multimodal lessons that powerfully shape children's literate identities occur mostly afterschool on corporate websites with global distribution highlights the pressing need for more research that examines the semiotic potential and power relations in children's play practices with web/toys. 


\section{References}

Boldt GM (2001) Failing bodies: discipline and power in elementary classrooms. Journal of Curriculum Theorizing, 17(4): 91-104.

Bourdieu P (1977) Outline of a Theory of Practice. Cambridge: Cambridge University Press.

Burke A and Rowsell J (2007) Assessing multimodal literacy practices. e-learning, 4(3): 329342.

Dyson AH (2003) The Brothers and Sisters Learn to Write: Popular literacies in childhood and school cultures. New York: Teachers College Press.

Goffman E (1971) Relations in Public: Microstudies of the public order. New York: Harper and Row.

Hill S (2009) Multiliteracies and the Early Years: Evaluation of mapping multiliteracies: A professional learning resource. Adelaide: University of South Australia.

Ito M (2007) Technologies of the Childhood Imagination: Media mixes, hypersociality, and recombinant cultural form. Médiamorphoses, 21. Retrieved June 2010 from http://documents.irevues.inist.fr/handle/2042/23561

Jenkins H, Purushotma R, Clinton K, Robison AJ and Weigel M (2006) Confronting the Challenges of Participatory Culture: Media education for the 21st Century. Chicago: The John D and Catherine T MacArthur Foundation.

Jewitt C (2006) Technology, Literacy and Learning: A multimodal approach. London: Routledge.

Kantor R and Fernie D (eds.) (2003) Early Childhood Classroom Processes. Cresskill, NJ: Hampton Press.

Knobel M and Wilbur D (2009) Let's Talk 2.0. Educational Leadership, 21-24.

Kress G (1997) Before Writing: Rethinking the paths to literacy. London: Routledge. 
Kress G (2009) What is mode? In C. Jewitt (Ed.), The Routledge Handbook of Multimodal Analysis (pp. 54-67). London: Sage.

Kress G and van Leeuwen T (1996) Reading Images: The grammar of visual design. London: Routledge.

Lave J and Wenger E (1991) Situated Learning: Legitimate peripheral participation. Cambridge: Cambridge University Press.

Leander KM and McKim KK (2003) Tracing the everyday 'sitings' of adolescents on the internet: a strategic adaptation of ethnography across online and offline spaces. Education, Communication and Information, 3(2): 211-240.

Leander KM and Sheehy M (eds.) (2004) Spatializing Literacy Research and Practice. New York: Peter Lang.

Lankshear C and Knobel M (eds.) (2007) The New Literacies Sampler. New York: Peter Lang. Luke A (1992) The body literate: discourse and inscription in early literacy training. Linguistics and Education, 4: 107-129.

Marsh J (2010) Young children's virtual play in online virtual worlds. Journal of Early Childhood Research, 8(1): 23-39.

Norris S. (2004). Analyzing Multimodal Interaction: A Methodological Framework. London: Routledge.

Rowsell J and Pahl K (2007) Sedimented identities in texts: instances of practice. Reading Research Quarterly, 42(3): 388-404.

Scollon R (2001) Mediated Discourse: The nexus of practice. London: Routledge. 
Scollon R and Scollon SW (2003) Discourses in Place: Language in the material world. New York: Routledge.

Scollon R and Scollon SW (2004) Nexus Analysis: Discourse and the emerging internet. New York: Routledge.

Shuler C (2007) D is for Digital: An analysis of the children's interactive media environment with a focus on mass marketed products that promote learning. New York: Joan Ganz Cooney Center at Sesame Street Workshop.

Steinkuehler CA (2004) Learning in Massively Multiplayer Online Games. Paper presented at the 6th international conference on learning sciences.

Vygotsky L (1935/1978) Mind in Society (A. Luria, M. Lopez-Morillas and M. Cole, Trans.). Cambridge, MA: Harvard University Press.

Wertsch JV (1991) Voices of the Mind: A sociocultural approach to mediated action. Cambridge, MA: Harvard University Press. 